\title{
Measurement of vertical strain and velocity at Siple Dome, Antarctica, with optical sensors
}

\author{
Mark A. ZUmberge, ${ }^{1}$ Daniel H. ElSberG, ${ }^{2}$ William D. HARrison, ${ }^{2}$ Eric HUSManN, ${ }^{1}$ \\ John L. MORAGK, ${ }^{2}$ Erin C. PETTIT, ${ }^{3}$ Edwin D. WADDINGTON ${ }^{3}$ \\ ${ }^{1}$ Scripps Institution of Oceanography, University of California, San Diego, La folla, California 92093-0225, U.S.A. \\ E-mail: zumberge@ucsd.edu \\ ${ }^{2}$ Geophysical Institute, University of Alaska Fairbanks, P.O. Box 757320, Fairbanks, Alaska 99775-7320, U.S.A. \\ ${ }^{3}$ Department of Earth and Space Sciences, Box 351310, University of Washington, Seattle, Washington 98195-1310, U.S.A.
}

\begin{abstract}
As part of a larger program to measure and model vertical strain around Siple Dome on the West Antarctic ice sheet, we developed a new sensor to accurately and stably record displacements. The sensors consist of optical fibers, encased in thin-wall stainless-steel tubes, frozen into holes drilled with hot water, and stretched from the surface to various depths (up to $985 \mathrm{~m}$ ) in the ice sheet. An optical system, connected annually to the fibers, reads out their absolute lengths with a precision of about $2 \mathrm{~mm}$. Two sets of five sensors were installed in the 1997/98 field season: one set is near the Siple Dome core hole (an ice divide), and a second set is on the flank $7 \mathrm{~km}$ to the north (the ice thickness at both sites is approximately $1000 \mathrm{~m}$ ). The optical-fiber length observations taken in four field seasons spanning a 3 year interval reveal vertical strain rates ranging from $-229 \pm 4 \mathrm{ppm} \mathrm{a}^{-1}$ to $-7 \pm 9 \mathrm{ppm} \mathrm{a}^{-1}$. In addition to confirming a non-linear constitutive relationship for deep ice, our analysis of the strain rates indicates the ice sheet is thinning at the flank and is in steady state at the divide.
\end{abstract}

\section{INTRODUCTION}

The depth distributions of vertical velocity and strain rate within an ice sheet, particularly near a deep coring site at an ice divide, are of interest for several reasons. The first, and perhaps most obvious, is that the strain rate is intimately connected with the rate of thinning of a layer of ice. If the layer is one of annual accumulation, for example, and its boundaries can be determined from core stratigraphy, then the annual accumulation can be determined from a flow model calibrated with strain-rate data (e.g. Cutler and others, 1995). Second, at a flow divide the flow is essentially vertical and the effective stress is low. Thus the vertical strain rate can be used to determine the flow law of ice in this regime, something that is poorly known and difficult to measure in the laboratory, yet important for many modeling studies. Finally, the vertical velocity at the surface, when compared with the accumulation rate, determines the rate of thickening or thinning of the ice sheet at the divide.

These were the motivations for measurements of vertical velocity and strain rate at Siple Dome, Antarctica $\left(82^{\circ} 39^{\prime} \mathrm{S}\right.$, $148^{\circ} 48^{\prime} \mathrm{W}$ ), which we began in $1997 / 98$ and will continue to 2001/02. Vertical velocity and strain are not standard measurements in glaciers and ice sheets, although several successful techniques have been reported. Most observations have been made in open boreholes by repeated measuring of the distance between natural or artificial markers in the borehole wall (Rogers and LaChapelle, 1974; Paterson, 1976; Raymond and others, 1994). Others have been made in refrozen boreholes by measuring the stretching of embedded markers (Harrison, 1975; Harrison and others, 1993). Because of the difficulty of making absolute measurements in the low- strain-rate regime at Siple Dome, we deployed two different types of sensor to give some redundancy. Both were of the embedded type. One system consisted of short-baseline $(1 \mathrm{~m})$ wire-resistance sensors (Harrison and others, 1993), and the other of a series of optical fibers extending from different depths to the surface. The wire-resistance sensors turned out to be sensitive to transients associated with their installation and are still approaching equilibrium. The new optical-fiber method and the results from it are described in this paper.

The technique of using optical fibers to monitor strain over long baselines was developed for borehole strain measurements on land (Zumberge and Wyatt, 1998) and for horizontal strain measurements on the sea-floor (Zumberge, 1997). Since they are fabricated from fused silica, optical fibers are fairly elastic and retain their optical qualities even when stretched by as much as $1 \%$ beyond their initial lengths. In an optical-fiber strainmeter, we take advantage of this property and fix the ends of a stretched optical fiber to the body whose strain we wish to monitor. The strain $\Delta L / L$ is averaged over the length interval spanned by the optical fiber (normally longer than $50 \mathrm{~m}$ ) and is simply the change in physical length $L$ of the optical fiber divided by its initial length.

\section{THE INSTRUMENTATION}

Electronic distance meters (EDMs) are standard surveying tools. They determine distances to remote reflectors by timing the round-trip travel time of light. Most emit intensitymodulated infrared light and can collect returns from reflectors placed several kilometers away. The most accurate EDMs can determine the light travel time with a precision 


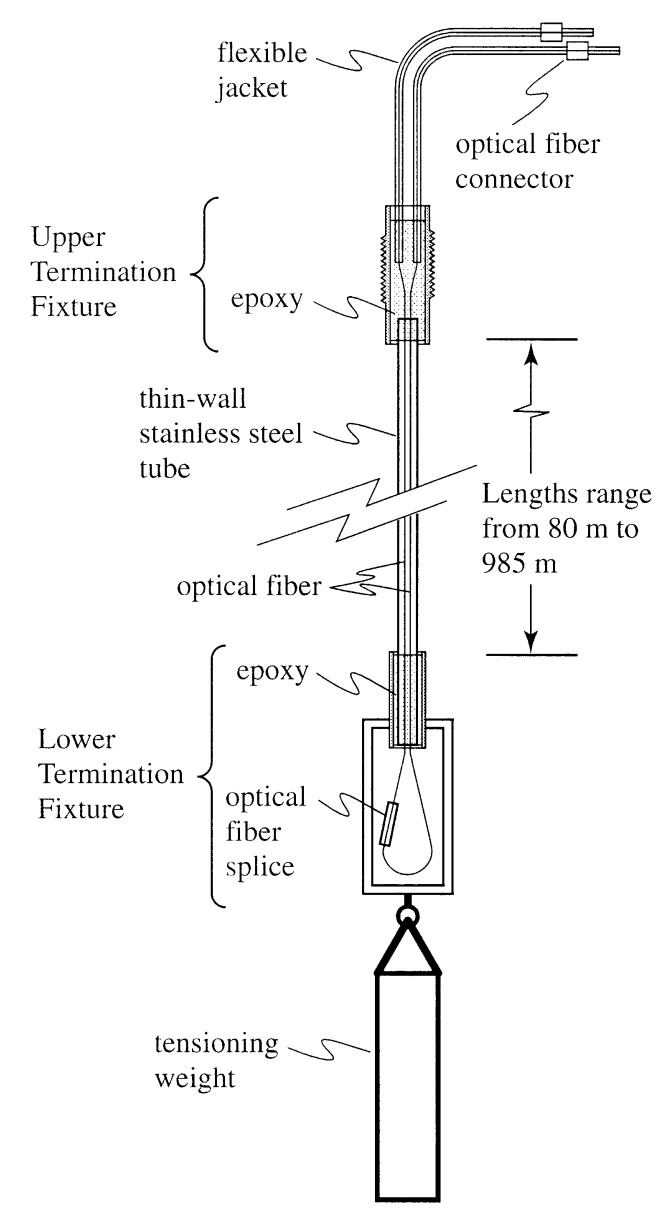

Fig. 1. Each sensor cable consists of a stainless-steel tube housing a round-trip loop of optical fiber, epoxied to terminations at both ends. The tube and fibers are stretched initially by means of a weight suspended at the lower end. After freeze-in, changes in length in the interval between upper and lower termination points are sensed optically.

adequate to infer the distance to the reflector to within \pm 1 or $2 \mathrm{~mm}$ over a few kilometers (Rüeger, 1990).

While these instruments are designed to operate through the atmosphere, they can be made to measure the length of an optical fiber by focusing the emitted beam into the fiber's core and coupling the light emerging from the fiber's other end into the EDM receiver optics. The distance reported by an EDM is the fiber's optical length, not its physical length. We desire the latter for strain measurements; the conversion from optical to physical length depends on the fiber's refractivity, which is a function of several factors, but most notably strain, temperature and wavelength.

The optical path length $L_{\mathrm{op}}$ of an unstressed fiber of physical length $L$ is given by

$$
L_{\mathrm{op}}=n L \text {, }
$$

where $n$ is the fiber's effective index of refraction. This effective index depends on the optical properties of the materials comprising the fiber and on the fiber's core diameter (for the SMF28 single-mode optical fibers used in our work, illuminated with light having a wavelength of $850 \mathrm{~nm}, n$ is 1.472; incidentally, at this wavelength the fiber actually supports more than one mode, but it was shown in Zumberge (1997) that extra modes are inconsequential). When strained, both the physical length and the effective $n$ change, the latter because of the strain-optic effect. The change in optical path length caused by straining the fiber follows from Equation (1),

$$
\Delta L_{\mathrm{op}}=n \Delta L+L \Delta n \text {. }
$$

Butter and Hocker (1978) showed that $\Delta n=k \varepsilon$, where $\varepsilon=\Delta L / L$ is strain and $k$ is a dimensionless constant whose value depends on the strain-optic coefficients of the materials used in the fiber (see their equation 5). Using representative values for these (Bertholds and Dandliker, 1988), one finds that $k=-0.31$. Combining these expressions with Equation (2) yields the simple relationship between optical path change $\Delta L_{\mathrm{op}}$ and physical length change $\Delta L$ :

$$
\Delta L_{\mathrm{op}}=(n+k) \Delta L \text {. }
$$

We define the coefficient $\nu \equiv n+k$ as the strain sensitivity of a fiber (Zumberge and others, 1988). It is simply the ratio of the optical length increase to the physical length increase. We determined experimentally that $\nu=1.16 \pm 0.01$. This agrees with the value predicted above from $\nu=n+k=$ $1.472-0.31=1.16$. For our Antarctic experiment, we measured $\nu$ in the laboratory by stretching sample fiber cables by a known distance while monitoring their optical lengths with the EDM, and we confirmed its value in cold field conditions after deploying the fiber cables by the same method. (Temperature effects are discussed below.)

\section{The optical-fiber cables}

Figures 1 and 2 show some of the details of the optical-fiber sensors and their installation; the schematic view of the optical-fiber cables (Fig. 1) shows several key aspects of these sensors and important details of their construction. The cables consist primarily of a pair of optical fibers $(125 \mu \mathrm{m}$ diameter fused silica coated with a plastic buffer to a diameter of $250 \mu \mathrm{m})$ encased loosely in a thin-wall stainless-steel tube (1.2 $\mathrm{mm}$ diameter, $0.13 \mathrm{~mm}$ wall thickness). At the cable's lower termination, the two fibers are fusion-spliced to each other. A cylindrical housing that can withstand hydrostatic pressure to $1000 \mathrm{~m}$ depth protects the splice. To provide mechanical terminations and fiducial points for the strain observations, the pair of fibers is epoxied to the inside of the tubing at either end: at the entrance to the pressure case at the lower termination fixture, and into a threaded fixture at the upper termination point. The fibers emerge from the top fixture through flexible protective sheaths (each about $1 \mathrm{~m}$ long) to polished optical-fiber connectors. These can be connected to an EDM mounted inside a portable instrument case (the "EDM box") along with the necessary focusing optics to couple light between the EDM and the fiber.

During the 1997/98 Antarctic field season, we installed our cables in a series of holes at two sites on Siple Dome. Referring to Figure 2, installation of the optical-fiber cables proceeded as follows: after the drilling of a hole was completed, several hours were available before it became inaccessible due to refreezing. A steel rebar weight $(5 \mathrm{~cm}$ diameter, $75 \mathrm{~cm}$ long) was suspended below the pressure case at the lower termination fixture of each fiber cable before it was spooled into the hole. The weight's mass $(12 \mathrm{~kg}$ ) was chosen to provide $0.1-0.2 \%$ initial elongation of the optical-fiber pair. This elongation depends primarily on the elastic modulus of the stainless-steel tubing. The top end of the cable was attached to a borehole "bridge" or fixture which established the upper end of the baseline over which vertical strain is monitored. After freeze-in, the weighted pressure case at the bottom end determined the lower end of the baseline. This 


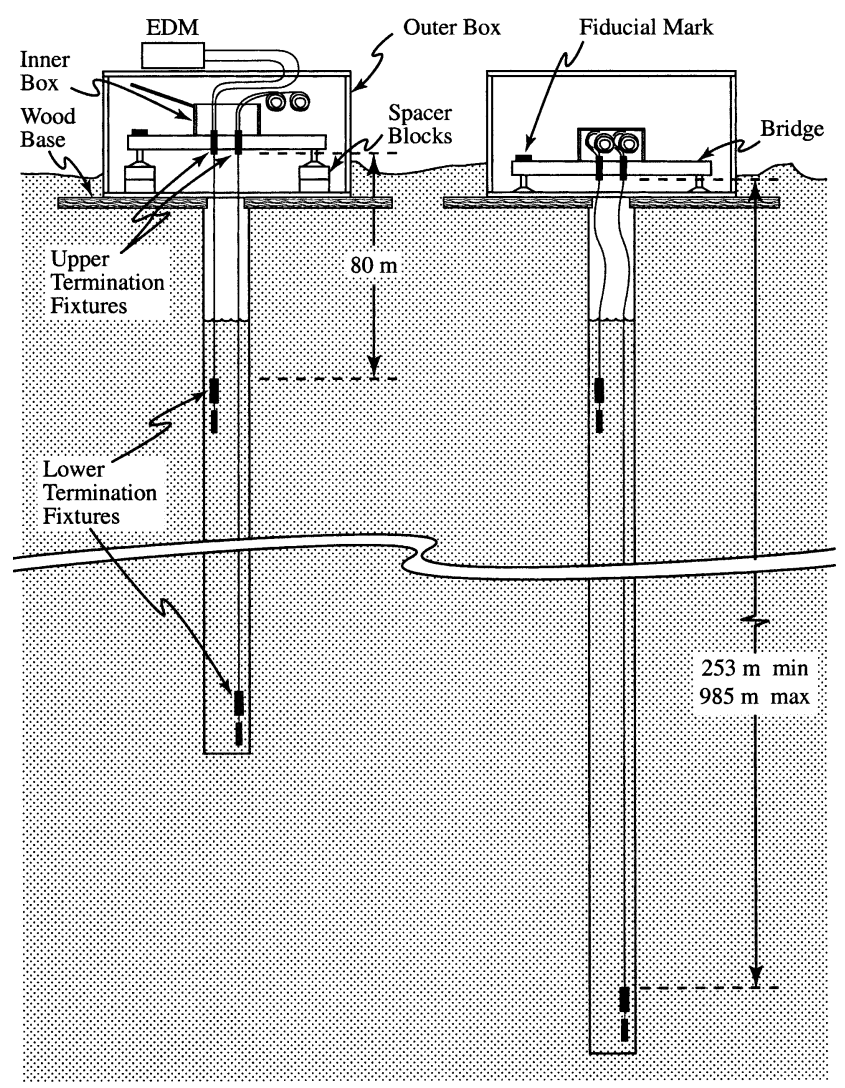

Fig. 2. Pairs of sensor cables were installed in holes drilled with hot water after the drill hose was removed and before the water refroze. For each pair, the lower termination of one sensor was shallow (80 $\mathrm{m}$ in all cases) and the other deep (ranging to bedrock). A bridge at the top of each hole supported the two sensor cables and housed the optical terminations in protective enclosures. After the firn in the upper layers compacted and the sensor cables slackened (as depicted in the pair of sensors on the right), tension was re-established by inserting spacer blocks beneath the bridge feet (left figure).

procedure resulted in a pair of optical fibers stretched between points fixed to the ice sheet at their ends and free to slide inside the stainless tubing over the intervening length. By connecting the optical fibers to the EDM box, the lengths of the individual cables can be determined in a few minutes.

Because the rate of compaction in firn is high compared to that at depth, we installed two fiber cables in each borehole: the first one to a depth ranging from 253 to $985 \mathrm{~m}$, the second one in all cases to $80 \mathrm{~m}$ - predicted to be $10-20 \mathrm{~m}$ below the depth of pore close-off. By subtracting the length record of the shallow fiber cable from that of the deep one, we effectively determine strain in the interval from the bottom end of the shallow cable $(80 \mathrm{~m})$ to the bottom end of the deep cable. Firn compaction, being common to the lengths of both cables, has no effect on the measured strain in this interval.

\section{The EDM box}

Figure 3 is a schematic drawing of the EDM box. A standard surveying EDM is mounted within an aluminum housing. Lenses focus two collimated light beams, one transmitted from the EDM and the other received. Situated at the focal points are optical-fiber bulkhead-connectors which accept the two fiber connectors during a length measurement. The lenses are mounted on translation stages to allow adjustment

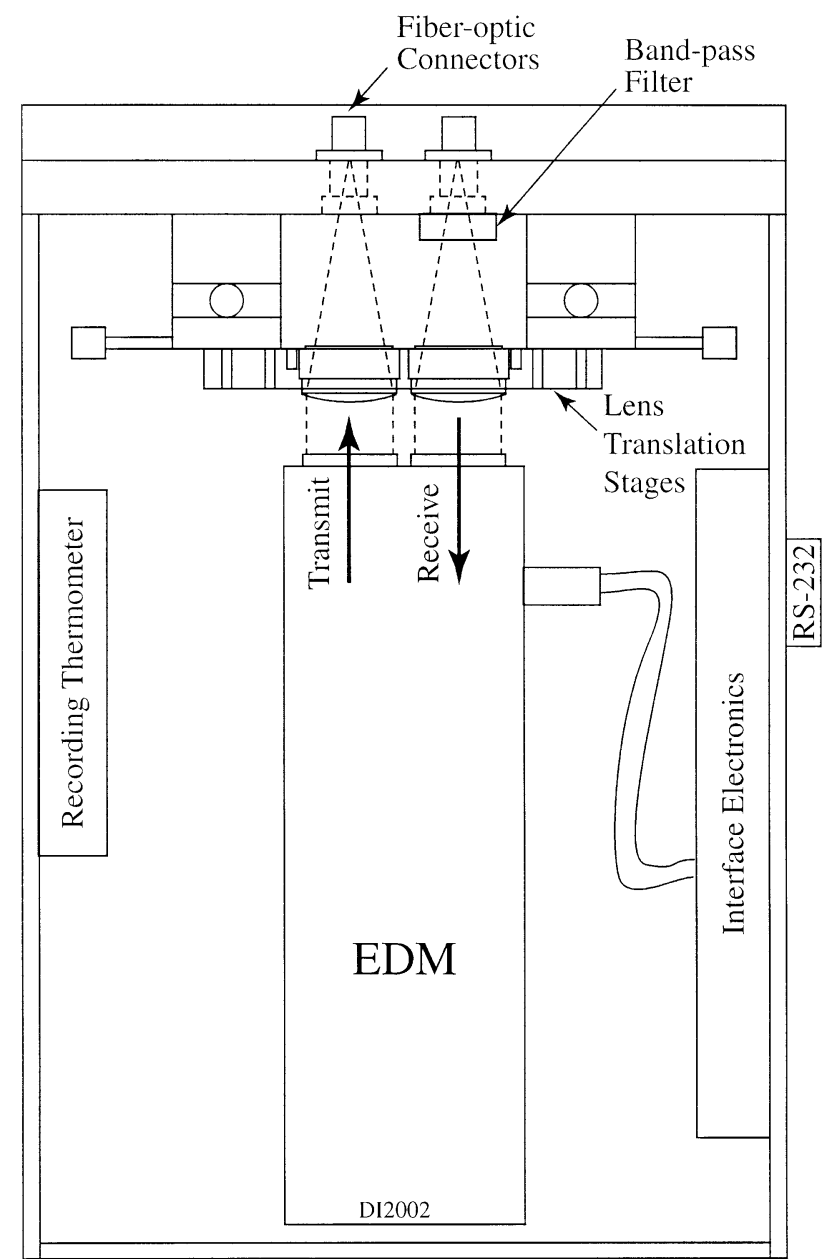

Fig. 3. A standard surveyor's EDM (Wild model DI2002) mounted in an aluminum enclosure that includes a temperature sensor, interface electronics and a pair of focusing lenses. The lenses couple light between the ends of the EDM and the optical-fiber loop. Lateral positions of the lenses are adjustable to optimize coupling of light into and out of the $10 \mu \mathrm{m}$ diameter optical-fiber core.

of the light being coupled into and out of the fiber. Connections on the side of the EDM box provide an interface to a portable controlling computer and batteries.

One issue that was found to be important in our earliest experiments with optical fibers and EDMs is dispersion. The EDM (a Wild DI2002) uses an $850 \mathrm{~nm}$ light-emitting diode as its light source. This has an optical line width of about $25 \mathrm{~nm}$, the center of which depends on temperature. Because the fiber's index of refraction is wavelength-dependent, changes in the EDM wavelength cause apparent length changes in the fiber. A $5 \mathrm{~nm}$ band-pass interference filter mounted inside the EDM box in the path of either beam is needed to prevent this (Zumberge, 1997).

\section{Temperature effects}

The optical path through a fiber of fixed length displays an apparent temperature coefficient because of the dependence of $n$ on temperature (and slightly because the core diameter of the fiber undergoes thermal expansion). This coefficient, $\alpha$, expressed in the form

$$
\alpha=\frac{1}{L} \frac{\mathrm{d} L_{\mathrm{op}}}{\mathrm{d} T}=\frac{\mathrm{d} n}{\mathrm{~d} T} \approx 1.2 \times 10^{-5}{ }^{\circ} \mathrm{C}^{-1}
$$

(Zumberge and others, 1988), is small enough that temperature variations over time in the deep portions of the borehole 


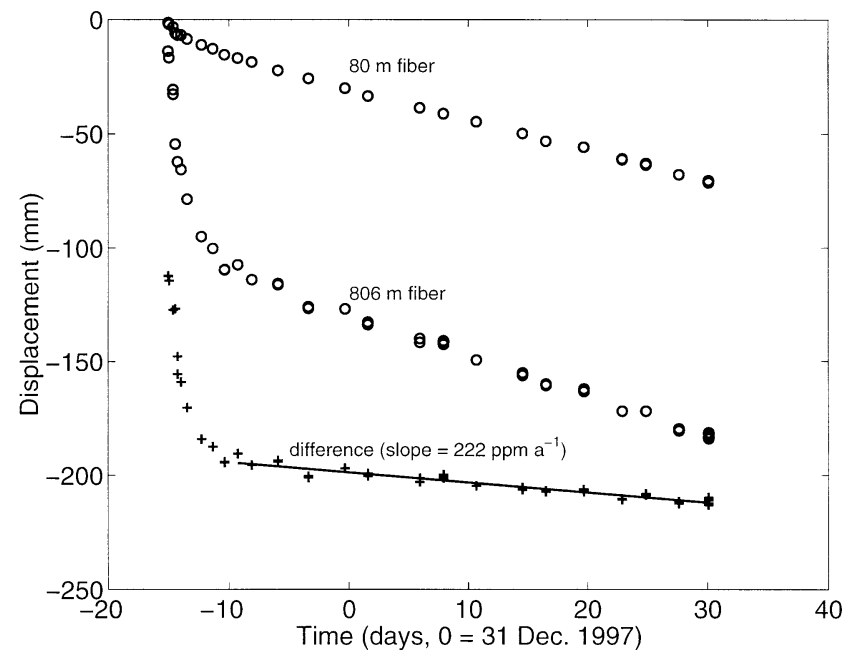

Fig. 4. Length records of two sensor cables (one shallow, one deep) beginning immediately after freeze-in. Temperature equilibration occurs before 2 weeks. The difference between the two displacement records (+) yields a slope representing the strain rate in the ice sheet in the depth interval defined by the two sensor cables' lower termination points: $80-806 \mathrm{~m}$ in this example (the offsets are arbitrary and adjusted for display purposes). In the experiment, we had ten such pairs, five at the divide site and five at the flank site.

have negligible effect (after 1 or 2 weeks of equilibration). Above the air-ice interface in the boreholes (typically at around $30-50 \mathrm{~m}$ depth, depending on the conditions of drill-water recovery), the pair of fiber strain sensors (one deep, one shallow) travel through air capable of significant temperature change. However, since we are differencing the measurements, it is only the difference in temperature profiles experienced by the two fiber cables that matters (i.e. horizontal temperature gradients have an effect, vertical gradients do not). Since they are within a few $\mathrm{cm}$ of one another (in the same borehole), it is unlikely that temperature contributes to the uncertainty. (From Equation (4), a $1.7^{\circ} \mathrm{C}$ lateral temperature difference would have to develop between the two fibers along the $50 \mathrm{~m}$ portion of the borehole exposed to air in order to cause a $1 \mathrm{~mm}$ differential error between observations.)

For measurements that are not differential (e.g. firn compaction and ice thinning rate discussed below), an additional temperature-uncertainty term must be added. The thermal characteristics of the firn cause the annual surface variation of $\pm 20^{\circ} \mathrm{C}$ to decrease to $<0.1^{\circ} \mathrm{C}$ at around $20 \mathrm{~m}$ depth (personal communication from G. D. Clow, 2000). This could cause an error of $2.4 \mathrm{~mm}$ in the optical path length of the fiber; this is a conservative estimate since we collect the data during the same season each year.

The temperature compensation of the EDM, stated by the manufacturer to be accurate to $1 \mathrm{ppm}$ over the full operating temperature range of the instrument $\left(-20^{\circ}\right.$ to $\left.50^{\circ} \mathrm{C}\right)$ should be adequate for our application. We were surprised, nevertheless, to see that the measurements in the field displayed a slight air-temperature dependence $\left(0.9 \mathrm{ppm}^{\circ} \mathrm{C}^{-1}\right)$. The cause of this was traced to the optical band-pass filter. Its pass band changes with the thermal expansion of the glass used to construct it, stated by the manufacturer to be $0.02 \mathrm{~nm}^{\circ} \mathrm{C}^{-1}$. This, when combined with the effect from dispersion reported in Zumberge (1997), yields an effect consistent with our observations. Fortunately, temperature in the EDM box was recorded for all of our measurements and we were able to make the correction. After the temperature effect was removed, the variance in measurements repeated at different temperatures dropped by $50 \%$.

\section{Field procedures}

After the hot-water drill rig was removed from above the hole, a deep fiber cable was spooled into the water-filled hole and was suspended from the bridge at the surface. Then the shallow fiber was spooled into the same hole and also fixed to the bridge. All of the installations proceeded smoothly, except for the deepest fiber at the divide site. The cable stopped spooling into the hole $3 \mathrm{~m}$ shallower than expected. We think this was due to an obstruction near the bottom of the hole (e.g. a rock), which was estimated to be about $20 \mathrm{~m}$ above bedrock. This resulted in an excess $3 \mathrm{~m}$ of fiber being stored under tension on a small spool fixed to the bridge.

Each bridge is mounted in a wooden box with a $0.50 \mathrm{~m} \times 1.22 \mathrm{~m}$ footprint. The wooden boxes were each set on a pair of $1 \mathrm{~m}^{2}$ plywood base platforms to help support them in the snow (Fig. 2). Also mounted on each bridge is a small, weatherproof housing in which the fibers, terminated with connectors, are stored. During read-out, the pair of fiber-ends from one of the two cables on the bridge are connected to the EDM box. A portable computer activates the EDM and records the optical length (this is repeated several times over a few minutes). Then the EDM box is connected to the second fiber and the procedure repeated. Five fiber-cable pairs in five separate boreholes (all within a few meters of one another) are read in a single visit. Several records spanning a period of up to 1 month were collected during each field season. Two such sites were installed on Siple Dome for a total of 20 fiber cables.

Figure 4 is an example of one of the records taken just after the fibers were installed. For a period of 1 or 2 weeks following installation, a decaying temperature signal is evident. Given the fiber temperature coefficient, $\alpha$, of $1.2 \times 10^{-5}{ }^{\circ} \mathrm{C}^{-1}$, a maximum fiber length of $985 \mathrm{~m}$ and a length resolution of $1 \mathrm{~mm}$, our measurements are sensitive only to temperature changes $>0.09^{\circ}$ C. Apparently, equilibrium within this value was reached soon after the installation since the transient dies away and the record shows a trend that is almost certainly linear after the 10th day. We attribute the slope thereafter primarily to firn compaction (discussed below), but strain in the deeper portion of the ice sheet also contributes.

With the displacement changing at the rate shown in Figure 4, the initial stretch put into the shallow $(80 \mathrm{~m})$ sensors (about $0.15 \%$ of $80 \mathrm{~m}$, or about $12 \mathrm{~cm}$ ) is exceeded within 1 year. This requires re-tensioning the fibers by raising the bridge at the beginning of each subsequent field season. We did this by adding wood blocks beneath the feet of the bridges until the vertical displacement of the bridge produced an observable length change in both fibers (i.e. when the slack caused by firn compaction, as shown schematically on the righthand side of Figure 2, was taken up). The displacement required to do this was recorded relative to a nearby marker with a local leveling survey precise to about $\pm 2 \mathrm{~mm}$.

\section{Stability tests}

Because this technique has not been tried before, we devoted significant effort to confirming the validity of the methodology. Of primary concern is the long-term stability of optical fibers. Zumberge and others (1988) measured the drift in a $25 \mathrm{~m}$ tensioned optical fiber with interferometry for a 77 day 

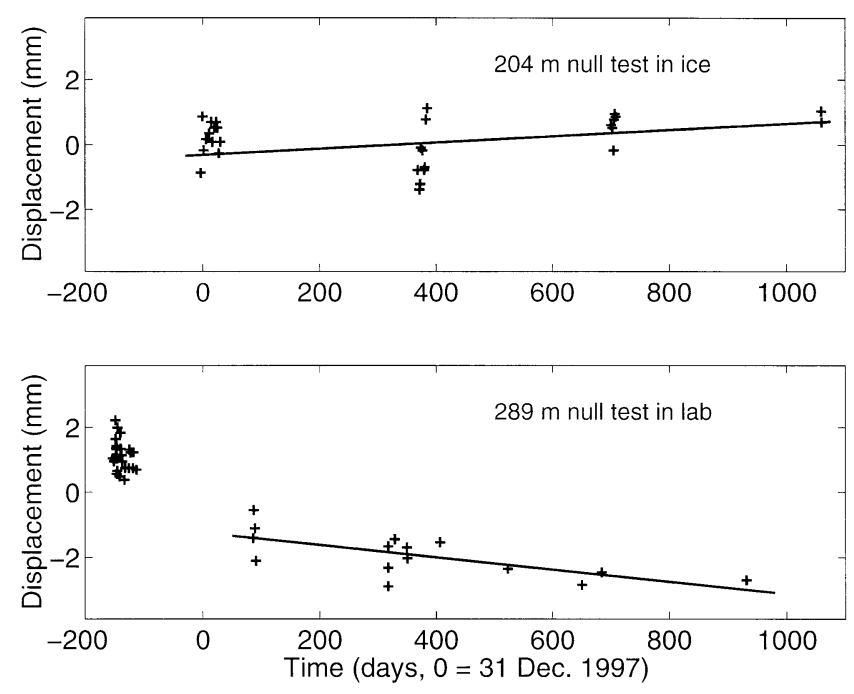

Fig. 5. Records of lengths of optical fibers wrapped around mandrels; we assume the lengths are constant within the limits of the materials comprising the mandrels. The fiber lengths are 407 and $577 \mathrm{~m}$, respectively. To compare these with the fiber cables measuring strain, we must halve these lengths since the EDM measures the round-trip distance through a loop of fiber.

period and found that the length was stable to $1.7 \mathrm{ppm} \mathrm{a}^{-1}$. Another important consideration is the calibration of the EDM. We monitored the frequency of its oscillator and found that it was stable within the manufacturer's specifications $\left(1 \mathrm{ppm} \mathrm{a}^{-1}\right)$.

While two key individual components appear to have the requisite stability on their own, a better test is one that evaluates the system stability, i.e. one in which the optical length of a fiber having constant physical length is monitored. In preparing for our Antarctic measurements, we wound loops of optical fiber on mandrels (one is on a $16 \mathrm{~cm}$ diameter brass cylinder, the other on a $13 \mathrm{~cm}$ diameter aluminum cylinder); one mandrel was wound with a $203 \mathrm{~m}$ loop of fiber and the other with a $289 \mathrm{~m}$ loop of fiber. We buried one fiber-wound mandrel in a protective PVC tube $3 \mathrm{~m}$ below the snow surface adjacent to our borehole fibers in Antarctica, and we measured its length simultaneously with the borehole fibers during each field season. The other one has been kept in a laboratory in San Diego since July 1997 and is periodically measured with the same EDM used in Antarctica. The length records for both are shown in Figure 5. Each of these had to be temperature-corrected using thermistors attached to the mandrels (the temperature in the laboratory and in the snow at a few meters' depth is much less stable than deep in the ice sheet). Slopes of these records (converted to strain) are $0.4 \mathrm{ppm} \mathrm{a}^{-1}$ and $-2.3 \mathrm{ppm} \mathrm{a}^{-1}$.

As a final experiment on stability, we stretched a spare $80 \mathrm{~m}$ fiber cable, identical to those used in the boreholes, between two anchors in the snow next to one of our strain sites and measured both its optical length and its physical length (using the EDM through the air) twice, with 1 year between measurements. The observed change in length of the optical fiber was $18.2 \pm 2 \mathrm{~mm}$, while the change in the physical distance between the anchors (caused by horizontal strain of the underlying ice sheet) was $17.0 \pm 2 \mathrm{~mm}$. The difference is $15 \pm 35 \mathrm{ppm}$. While the uncertainty in this test is higher than those of the mandrel tests, it mimics the actual sensors more closely and serves to show that there are no large unexpected errors.

A minor but important point is that the tensioning weight on one of the shallow fibers was twice that of all of the others. The agreement, to within a few mm, of that fiber's length record with neighboring shallow fibers (see below) indicates that creep through the ice of the frozen-in tensioning weights was insignificant.

One more test worth mentioning is examination of the fibers during the second and third field surveys with an optical time-domain reflectometer (OTDR), a standard tool for evaluating optical fibers. In an OTDR, the arrival times of backscattered photons in the optical fiber under test are recorded and displayed. The optical signal attenuation, and losses due to splices and reflections, are determined in this way. To within the resolution of the instrument, no degradation or other changes in any of the optical fibers were seen.

\section{RESULTS}

Our data consist of the vertical displacement of fiber sensors with respect to the wood bases at the surface. In addition, the wood bases are tied to global positioning system (GPS) reference poles installed in 1995 (Hamilton and others, 1998) by optical leveling. From this dataset, we examine the dynamic vertical strain at depth due to ice flow by calculating the displacement of the long fibers with respect to the short fibers. The experimental set-up also allows us to measure the compaction of the top $80 \mathrm{~m}$ of the firn column by comparing the shortest fibers to our surface markers.

\section{Calculations and errors}

The five $80 \mathrm{~m}$ fibers installed at each site allow the effect of firn compaction to be subtracted from the strain measurements, but they also provide a means to determine the displacements of five redundant intervals with respect to a point on the surface, a measurement of firn compaction. Table 1 lists the displacements seen at our two sites by the five independent, $80 \mathrm{~m}$ long fiber sensors. The displacements are, essentially, the downward motion of markers at the surface with respect to terminations frozen in at depths of $80 \mathrm{~m}$ (displacements are defined as zero on day 25 in Table 1). Two

Table 1. Displacements of surface markers relative to anchors frozen in at $80 \mathrm{~m}$ depth, each determined with identical opticalfiber cables. We refer the displacements both to the original wood bases installed at the time of the drilling and to an external reference marker used for GPS surveys

$$
\begin{aligned}
& \text { Cumulative displacement } \\
& \text { Fib. } \mathcal{N}_{0} \quad \text { w.r.t. GPS poles wood base }
\end{aligned}
$$

Day 25 Day 382 Day 704 Day 1058 Day 382 Day 704 Day 1058

\begin{tabular}{|c|c|c|c|c|c|c|c|}
\hline & & $\mathrm{mm}$ & $\mathrm{mm}$ & $\mathrm{mm}$ & $\mathrm{mm}$ & $\mathrm{mm}$ & $\mathrm{mm}$ \\
\hline Divide & & & & & & & \\
\hline 1 & 0 & -213.8 & -391.3 & -589.8 & -271.0 & -471.0 & -691.8 \\
\hline 2 & 0 & -209.1 & -388.2 & -576.1 & -276.1 & -481.2 & -703.1 \\
\hline 3 & 0 & -212.1 & -392.3 & -589.7 & -278.1 & -488.3 & -717.7 \\
\hline 4 & 0 & -208.0 & -388.4 & -587.0 & -284.0 & -494.4 & -728.0 \\
\hline 5 & 0 & -213.1 & -392.0 & -586.4 & -292.1 & -500.0 & -721.4 \\
\hline Flank & & & & & & & \\
\hline 6 & 0 & -243.2 & -445.3 & -665.0 & -314.2 & -549.3 & -800.0 \\
\hline 7 & 0 & -245.3 & -449.5 & -661.2 & -310.3 & -542.5 & -789.2 \\
\hline 8 & 0 & -245.3 & -447.9 & -666.0 & -323.3 & -559.9 & -813.0 \\
\hline 9 & 0 & -242.3 & -449.3 & -667.5 & -304.3 & -540.3 & -797.5 \\
\hline 10 & 0 & -245.6 & -449.7 & -670.8 & -327.6 & -566.7 & -823.8 \\
\hline
\end{tabular}


reference datums, registered to one another with optical leveling, are listed in the table. First, we list the GPS reference poles near our sites (110 m away at the divide site, $60 \mathrm{~m}$ away at the flank) installed in 1995 (Hamilton and others, 1998). Second, we list the displacements of our wood-base platforms installed in 1997. The standard deviations of the two sets of fibers at three epochs range from 1.5 to $5.6 \mathrm{~mm}$ when referenced to the GPS poles; when referenced to the wood platforms, the variability is around $1 \mathrm{~cm}$. It is not surprising that referring all of the fibers to a single datum (the GPS pole) rather than five datums (one set of wood platforms for each of five fibers) shows smaller scatter. We attribute the higher variability of the wood platforms to their differential settling in snow that had been disturbed by the drilling operation. Also note that the downward velocity of the GPS poles installed 2 years earlier is smaller than that of the wood platforms. The wood platforms are moving downward with the 1997 snow surface, while the GPS poles are anchored deeper in the firn column. The wood platforms experience additional downward motion due to compaction of snow between the 1997 surface and the anchor depth of the GPS pole. Thus, the wood platforms have a larger measured downward velocity.

In addition to comparing the surface markers to the $80 \mathrm{~m}$ fibers, it is useful to compare the surface markers to the deepest fiber. In Table 2, we list the vertical velocities of our surface markers with respect to our shallowest and deepest anchors. We estimate the uncertainty to be $12 \mathrm{~mm}$ $\mathrm{a}^{-1}$ for all of the velocity values listed, calculated with the quadrature sum of three terms: the differential settling of our wood bases evident from Table $1(10 \mathrm{~mm})$, the uncertainty in the EDM measurements $(5 \mathrm{~mm}$ for the fibers to the bed and $2 \mathrm{~mm}$ for the $80 \mathrm{~m}$ fibers), and the near-surface temperature effect $(2.4 \mathrm{~mm})$ added because the measurements are not differential. The error is dominated by the variability among surface markers. This effect is difficult to assess, and we do not know to what extent the drilling operation disturbed the underlying snow.

Figure 6 displays the strain at depth for the entire array of fiber-optic sensors spanning a 2.8 year period. For each sensor, we have differenced the lengths recorded for pairs of fiber cables (one deep and one shallow in each case). The slope from a linear least-squares fit to each record is the integrated strain rate over the intervals shown. To obtain the variation in strain rate with depth, the slopes in Figure 6 are differenced

Table 2. Vertical velocities averaged for three periods

\begin{tabular}{lccc} 
Reference points & \multicolumn{3}{c}{ Average vertical velocity } \\
& Year 1 & Year 2 & Year 3 \\
$\mathrm{~mm} \mathrm{a}^{-1}$ & $\mathrm{~mm} \mathrm{a}^{-1}$ & $\mathrm{~mm} \mathrm{a}^{-1}$ \\
\hline
\end{tabular}

Divide site

Wood base to $80 \mathrm{~m}$

GPS pole to $80 \mathrm{~m}$

Wood base to $985 \mathrm{~m}$

GPS pole to $985 \mathrm{~m}$

$\begin{array}{lll}-287 & -234 & -233 \\ -216 & -203 & -202 \\ -394 & -344 & -326 \\ -313 & -312 & -298\end{array}$

Flank site

Wood base to $80 \mathrm{~m}$

GPS pole to $80 \mathrm{~m}$

Wood base to $948 \mathrm{~m}$

GPS pole to $948 \mathrm{~m}$

$\begin{array}{lll}-323 & -267 & -261 \\ -250 & -231 & -225 \\ -493 & -431 & -403 \\ -409 & -392 & -366\end{array}$

Notes: The values have been normalized to lyear intervals from actual intervals of: day 25 to day 382 (year 1), day 382 to day 704 (year 2), and day 704 to day 1058 (year 3). Day 1 is 1 January 1998.
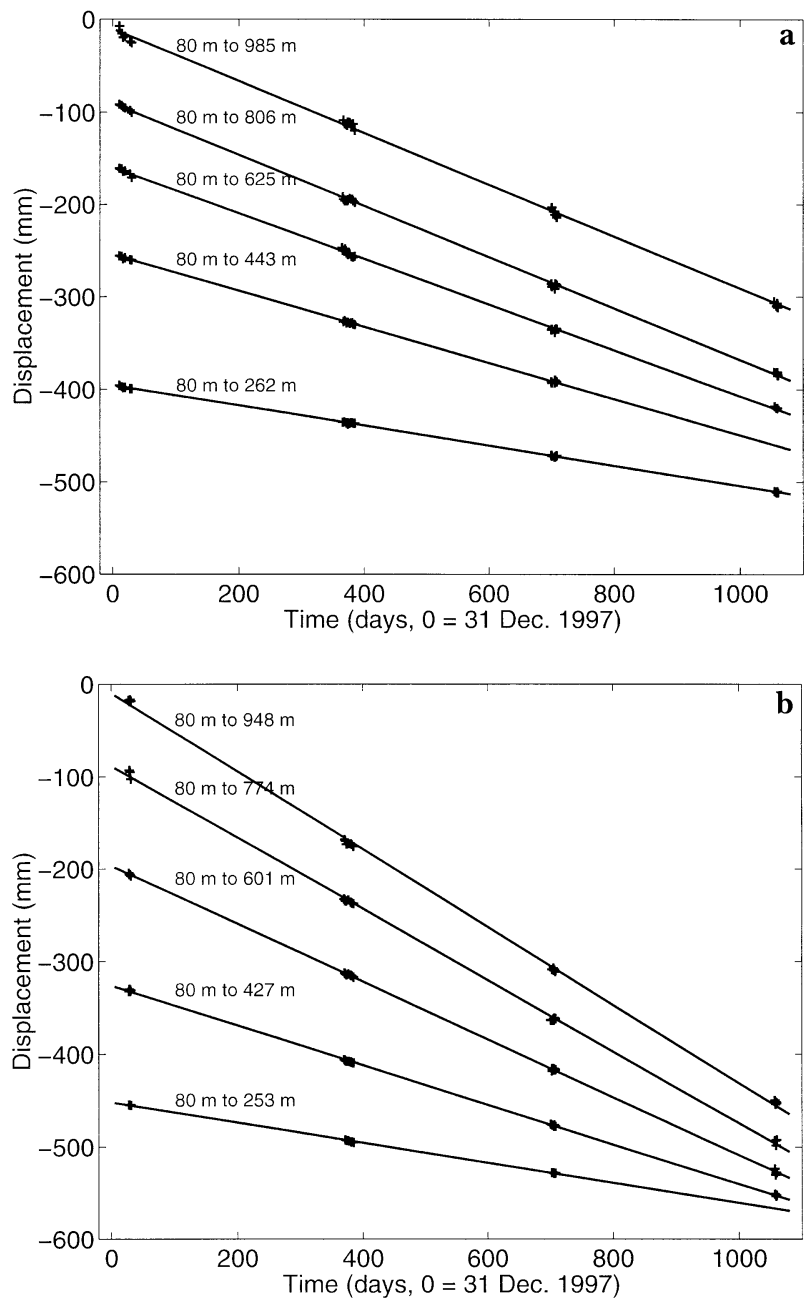

Fig. 6 . The results of four field seasons of strain measurement at the divide site ( a) and at the flank site ( $b$ ). Plotted in each graph are the differences in length (deep minus shallow) for pairs of sensor cables in five boreholes. Symbols are +'s, representing repeated measurements (some are nearly indistinguishable from one another).

(or, equivalently, the displacements of the individual fibers are differenced), giving the results listed in Table 3 and plotted in Figure 7. The overall $\mathrm{rms}$ residual to the linear fits is $2.4 \mathrm{~mm}$; for individual cables, this ranged from 0.7 to $3.7 \mathrm{~mm}$. (We

Table 3. Strain derived from subtraction of neighboring slopes in Figure 6

\begin{tabular}{|c|c|}
\hline Depth interval & Strain rate \\
\hline $\mathrm{m}$ & $\mathrm{ppma}^{-1}$ \\
\hline \multicolumn{2}{|l|}{ Divide site } \\
\hline $80.0-261.5$ & $-219 \pm 3$ \\
\hline $261.5-443.0$ & $-174 \pm 7$ \\
\hline $443.0-624.7$ & $-105 \pm 9$ \\
\hline $624.7-806.4$ & $-61 \pm 7$ \\
\hline $806.4-985.0$ & $-7 \pm 9$ \\
\hline \multicolumn{2}{|l|}{ Flank site } \\
\hline $80.0-253.5$ & $-229 \pm 4$ \\
\hline $253.5-427.1$ & $-222 \pm 7$ \\
\hline $427.1-600.8$ & $-206 \pm 5$ \\
\hline $600.8-774.4$ & $-155 \pm 7$ \\
\hline $774.4-948.1$ & $-74 \pm 9$ \\
\hline
\end{tabular}

Note: In these measurements, firn compaction and temperature effects above $80 \mathrm{~m}$ depth affect all sensors equally and are inconsequential. 


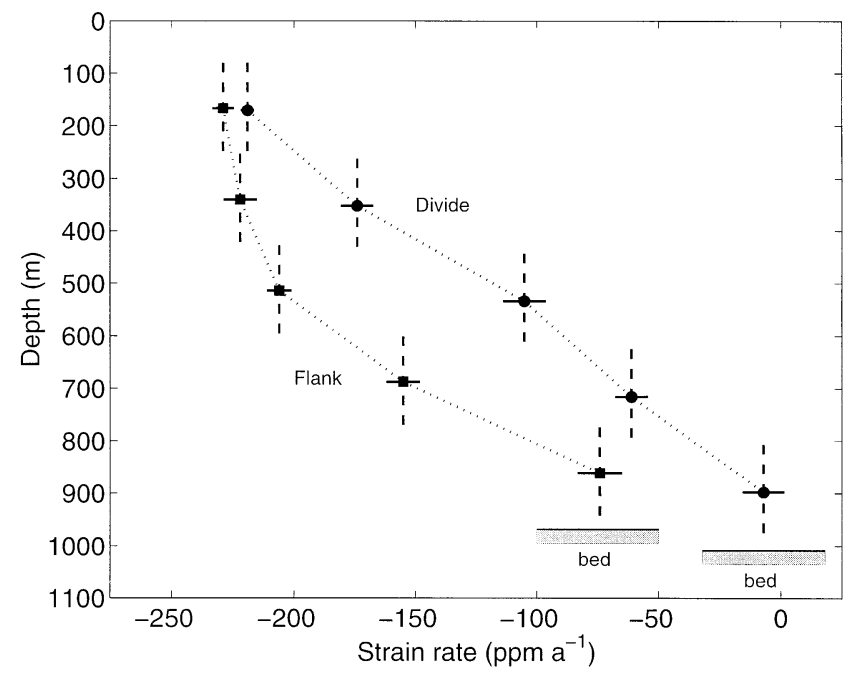

Fig. 7. Strain rate as a function of depth for the depth intervals defined by lower termination points of pairs of deep sensor cables. These were computed from differences between slopes in Figure 6. The uncertainty in each strain-rate determination is shown by a horizontal error bar; the dashed vertical line drawn through each point is not the uncertainty in the depth coordinate; rather it indicates the depth range over which strain rate is averaged for each determination (the points are plotted at the mean depth of each interval).

excluded data collected in the fourth field season for two of the ten fiber installations because of suspected tensioning problems.) A histogram of the residuals is shown in Figure 8.

Uncertainties in the strain rates are estimated from the displacement uncertainties and the rms residuals to the linear fits of displacement vs time. Sources of displacement uncertainty include that inherent to the EDM (1.0-1.4 mm, depending on the cable length), the error resulting from differencing two adjacent length measurements, and uncompensated temperature effects (estimated $1 \mathrm{~mm}$ ). These uncertainties and the rms residuals to the fits were summed in quadrature and divided by the duration of the experiment to date (2.8 years; data collection will continue to further improve slope estimates). This, when divided by the depth interval separating adjacent fibers (approximately $200 \mathrm{~m}$ ), yields the uncertainty in ppm a ${ }^{-1}$ listed in Table 3. Deeper strain intervals are more uncertain because we are differencing larger numbers with proportionally larger uncertainties.

At the flank site, the borehole in which we placed the instruments underwent horizontal shear deformation as well as vertical compression. We have modeled the evolution of the borehole to determine the amount of the measured strain rate that is due to horizontal shearing. Because the holes are vertical rather than bed-normal, instruments in the borehole initially undergo a shortening as the shearing flow rotates the holes toward bed-normal; later, the bottom section of the borehole begins to experience elongation as the hole rotates past the bed-normal orientation. The amount of measured strain in the fibers that is due to horizontal shearing of the borehole is predicted to be less than can be detected with our current level of uncertainty.

\section{Interpretation}

Firn-compaction rates are difficult to measure experimentally, and thus are often calculated from depth-density profiles under the assumption that the profiles have been constant with

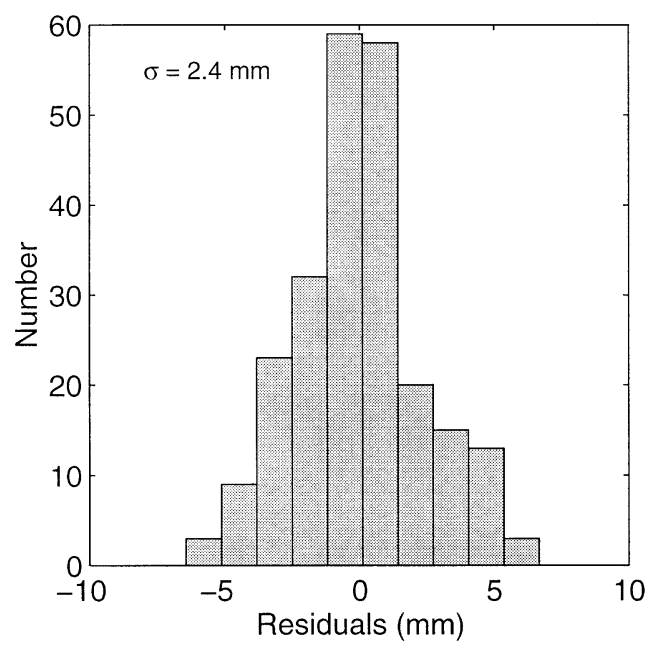

Fig. 8. Histogram showing the residuals after linear fits to the data plotted in Figure 6.

time (Sorge's law; e.g. Paterson, 1994, p. 14). Actual measurements of firn compaction (e.g. Raymond and others, 1996; R. L. Hawley and others, unpublished information) are rare. Firn-compaction rates are crucial to interpreting laser altimetry data in terms of an ice sheet's mass balance (Wingham and others, 1998). Our measurements, shown in Table 2 as the average downward vertical velocity of the wood base and the GPS pole relative to the $80 \mathrm{~m}$ fiber sensor, provide an estimate of the total vertical thinning of the top $80 \mathrm{~m}$ of the ice sheet. This total vertical strain has two components. The measurements are dominated by firn compaction, but there is also dynamic thinning due to ice flow.

Table 2 also shows the vertical velocity of the wood base and GPS pole relative to the deepest fibers. Since these fibers are near the bed (within $20 \mathrm{~m}$ of the bed at the divide site and $40 \mathrm{~m}$ at the flank), it is reasonable to assume that these anchors are almost stationary with respect to the bedrock. This allows us to measure directly the motion of the surface of the ice sheet (the GPS poles) relative to bedrock.

In a steady-state glacier, the total dynamical thinning of the ice sheet must be balanced by the ice equivalent accumulation rate. Our measurements allow us to test Siple Dome for steady-state behavior. The vertical velocities of the fiber anchors at $80 \mathrm{~m}$ depth relative to the deepest fibers are 10.2 and $15.3 \mathrm{~cm} \mathrm{a}^{-1}$. These values are approximately equal to the measured accumulation rate at the surface in ice equivalent units at each site: $11 \mathrm{~cm} \mathrm{a}^{-1}$ at the divide and $14 \mathrm{~cm} \mathrm{a}^{-1}$ at the flank (Nereson and others, 2000). This behavior suggests that the ice sheet may be close to steady state. This comparison, however, assumes that the small amount of dynamic vertical thinning in the upper $80 \mathrm{~m}$ is negligible and that the deep fibers are stationary with respect to the bed. The former assumption could be questioned because it ignores the strain in $6 \%$ of the ice equivalent thickness of the ice sheet. The latter assumption could be questioned because there is a finite strain between the fiber anchor and the bedrock, and the calculation puts all the weight on one data point (the deepest fiber). Thus, this is a suggestive but not definitive test for steady-state behavior.

Using our complete profile of vertical strain rate vs depth (Fig. 7), we can examine this more fully without making these two assumptions. We derive a theoretical thinning rate $\dot{H}(x)$ for the ice sheet by fitting our measurements of vertical strain rate to a flow model. We approximate Siple Dome as a linear 

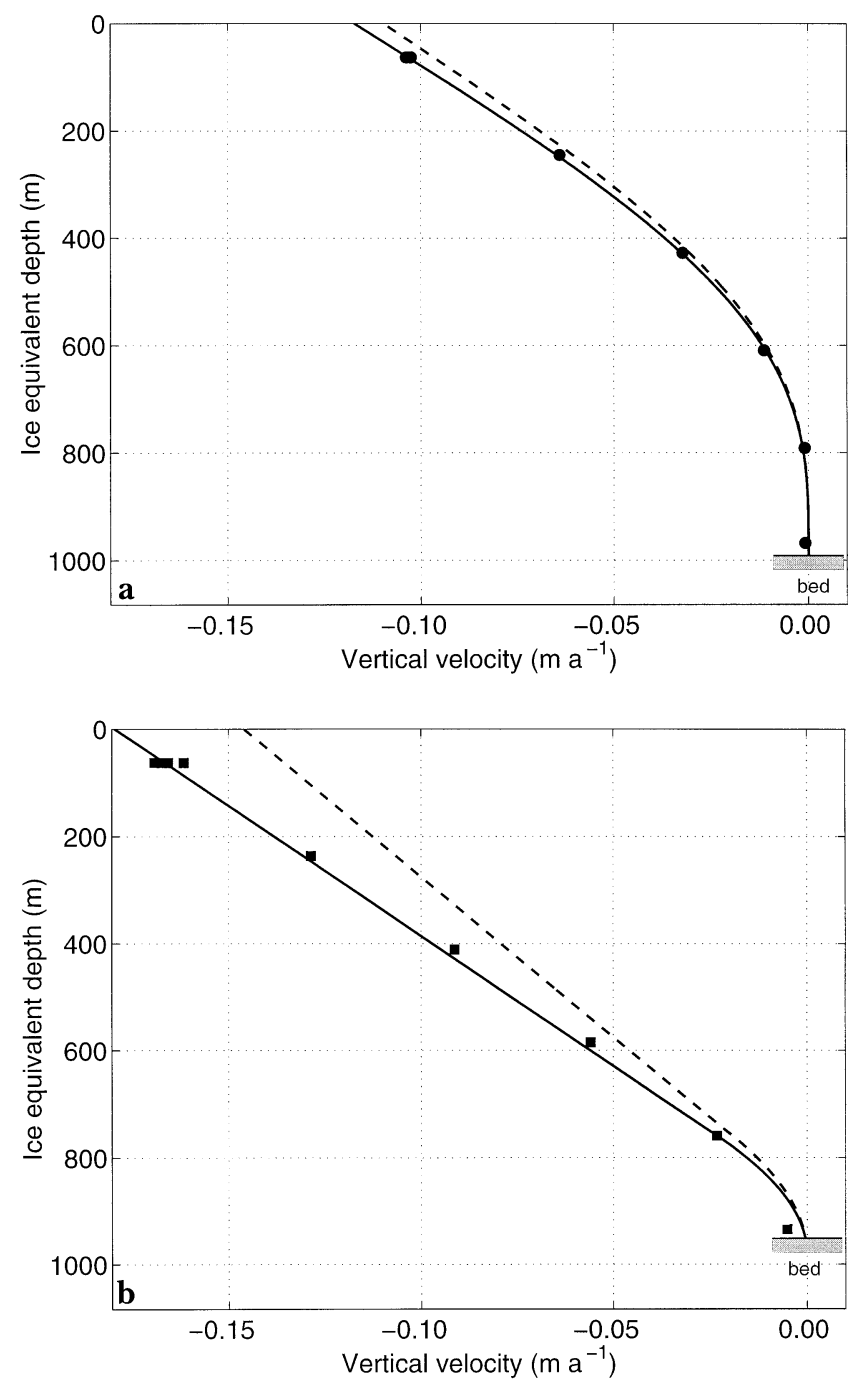

Fig. 9. Modeled vertical velocities as functions of ice equivalent depth at the divide site ( $a$ ) and the flank site ( $b$ ). The solid curve is the best fit of Equation (5) to our measurements. The dashed curve is Equation (5) for $\dot{H}=0$.

ridge and model it in cross-section as a two-dimensional plane flow. Using the shape function method of Reeh (1988), the vertical velocity is expressed by

$$
\begin{aligned}
w(x, \eta)= & -[\dot{b}(x)-\dot{H}(x)] \psi(\eta) \\
& +u_{\mathrm{s}}(x) \phi(\eta)\left(\frac{\mathrm{d} B}{\mathrm{~d} x}+\eta \frac{\mathrm{d} H}{\mathrm{~d} x}\right),
\end{aligned}
$$

where $x$ is horizontal position, $\dot{b}(x)$ is the accumulation rate, $B(x)$ is the bed elevation, $H(x)$ is the thickness in ice equivalent units (as if the firn had been compacted to an ice layer, reducing its thickness by $17.3 \mathrm{~m}), \dot{H}(x)$ is its rate of change, $u_{\mathrm{s}}(x)$ is the horizontal velocity at the surface, $\eta$ is the height above the bed scaled to the local ice thickness $H(x)$, and $\phi(\eta)$ and $\psi(\eta)$ are the shapes of the horizontal and vertical velocity profiles, respectively. For $\phi(\eta)$ and $\psi(\eta)$, a Dansgaard-Johnsen velocity model (Dansgaard and Johnsen, 1969) is applicable at the flank site. The horizontal velocity shape $\phi(\eta)$ is constant in the upper part of the ice sheet (above height $h$ above the bed) and decreases linearly to zero between height $h$ and the bed. Using the value of $h=227 \mathrm{~m}$ recommended by Nereson and others (1996), and their measured values of $B(x), H(x)$ and $u_{\mathrm{s}}(x)$, we found the value of $\dot{b}(x)-\dot{H}(x)$ necessary to best fit the slope of the vertical velocity (Equation (5)) to our vertical strain-rate data in a least-squares sense.

At the divide, however, the Dansgaard-Johnsen model does not satisfy the boundary condition that $\mathrm{d} u / \mathrm{d} z=0$ at the bed (Raymond, 1983; Reeh, 1988). The horizontal velocity profile, $\phi(\eta)$, at the divide must have an inflection point such that it is concave upward in the upper part of the ice sheet and concave downward near the bed. This curvature results in a vertical velocity profile, $\psi(\eta)$, that is steeper in the lower part of the ice sheet than the Dansgaard-Johnsen model permits. We modified the analytical expression for vertical velocity shape function at a flow divide from Reeh (1998, equation (32)) by including a steady-state temperature profile with vertical advection (Paterson, 1994) using a surface temperature of $-25^{\circ} \mathrm{C}$ and a bed temperature of $-2^{\circ} \mathrm{C}$. This is a good approximation to the measured profile (personal communication from G. D. Clow, 2001). We then used this shape function to find the best-fitting value of $\dot{b}(x)-\dot{H}(x)$. Because $u_{\mathrm{s}}(x)=0$ at the divide, we did not need to derive the corresponding temperature-dependent forms of $\phi(\eta)$ in Equation (5). The solid curves in Figure $9 \mathrm{a}$ and $\mathrm{b}$ are these best-fitting models (Equation (5) using these values of $\dot{b}(x)-\dot{H}(x))$.

Since the calculations above use only the velocity differences, we needed to assign an absolute velocity to each pair of data points in order to plot them for comparison with the best-fitting model. We minimized the mismatch between the unknown absolute velocities of each pair (whose velocity difference we know) and the model curves in Figure 9a and $b$. Note that the spread of the inferred velocities of the short-fiber anchors (at approximately $80 \mathrm{~m}$ depth) falls within the uncertainties discussed above. For comparison, the dashed line is Equation (5) assuming the ice sheet is in steady state with the measured current accumulation rate, that is, $\dot{H}=0$.

At the divide, the best-fitting model predicts $\dot{b}(x)$ $-\dot{H}(x)=12 \mathrm{~cm} \mathrm{a}^{-1}$ (ice equivalent), which agrees with the measured steady-state accumulation rate $\dot{b}(x)$ to within its measurement uncertainty. Thus, the thickening rate, $\dot{H}(x)$, is indistinguishable from zero. The flank site, however, requires a significantly higher $\dot{b}(x)-\dot{H}(x)$ than the measured accumulation rate $\left(\dot{b}(x)=14 \mathrm{~cm} \mathrm{a}^{-1}\right)$. This suggests that the flank site may be thinning by as much as $3 \mathrm{~cm} \mathrm{a}^{-1}$. Nereson (1998) calculated the vertical velocity at the surface of Siple Dome using the divergence of the surface horizontal velocity as measured by GPS on a survey grid. Her results, which apply only to the divide site, agree with ours: the divide site is in steady state. A similar horizontal divergence calculation has not yet been completed for the flank site.

In addition to studying the steady-state behavior of Siple Dome, our depth profile of vertical strain rate has more general implications for the flow of ice near ice divides. The widely used rheological relation for ice sheets, known as Glen's flow law (Glen, 1958), relates strain rate to the third power of the deviatoric stress. This non-linear relation was derived and tested using a combination of laboratory experiments and measurements on glaciers, all of which were carried out at relatively high stress levels. This third-power law has been challenged on occasion (e.g. Doake and Wolff, 1985; Wolff and Doake, 1986) in favor of a linear viscous rheology. Waddington and others (1996) suggested that a flow law with both a linear and a non-linear term (as first proposed by Meier, 1958) might be required to describe deformation at an ice divide where deviatoric stresses are small. Using groundpenetrating radar, Vaughan and others (1999) demonstrated 
that at least for near-surface polar ice, non-linear behavior is clearly present. Our results show that deeper ice also displays non-linear behavior.

Ice described by Glen's law has an effective viscosity that increases with decreasing deviatoric stress. Deep under an ice divide like Siple Dome, deviatoric stresses are so low that there should be a region of very stiff ice near the bed. When using Glen's law, Raymond (1983) predicted reduced vertical strain rates in the bottom half of the ice sheet at an ice divide where the ice is stiff compared to the flanks. He also found a more linear vertical strain-rate profile at the divide compared to the flanks. However, with a linear constitutive relation, the vertical strain-rate profiles under a divide and under a flank should be indistinguishable. Figure 7 shows distinct differences between the vertical strain-rate profiles at the ice divide and at the flank. We find significantly smaller vertical strain rate between 400 and $900 \mathrm{~m}$ under the divide, and a more linear profile of vertical strain rate overall compared to the flank site, confirming that deep polar ice at Siple Dome expresses non-linear behavior. Whether a linear term, as suggested by Waddington and others (1996), is also detectable in our results awaits a more refined analysis.

\section{GONGLUSIONS}

We have accomplished four goals in this project. First, we have developed a new tool for measuring vertical strain rates. Second, we have obtained a direct measurement of the present-day vertical velocity pattern near a deep polar ice-core site; this will prove to be useful for interpreting the Siple Dome core. Third, we have confirmed from direct measurements that the constitutive relationship for deep ice has a non-linear component. Finally, we have provided a new estimate of the rate of ice-thickness change at Siple Dome. We plan to collect more data from the fiber strainmeters, and we expect that results from the co-located wire strain meters will further elucidate the pattern of vertical strain rate at depth near an ice divide.

The new optical-fiber technique described here has proven to be effective at tracking vertical displacements of points in an ice sheet ranging from the surface to the bed. The precision is a few $\mathrm{mm}$. In addition to providing a means to measure vertical strain within the ice, the technique may also prove useful for linking surface geodetic observations to the bedrock.

\section{ACKNOWLEDGEMENTS}

We are indebted to H. Engelhardt and the California Institute of Technology hot-water drilling crew for preparing the boreholes used in this research. Key information on details of EDM technology was provided by $\mathrm{H}$. Ehbets of Leica AG, Heerbrugg, Switzerland; important advice on stainless-steel encased optical fibers was provided by C. Theodossi of Armortech, Inc., San Diego. Thanks to C. F. Raymond for discussions about the project and for his careful reading of the manuscript. Careful reviews by R. LeB. Hooke (Scientific Editor), W. de Waele and N. Reeh helped us correct some errors in the manuscript, and, in the case of Reeh's comments, led to a better fit to the modeled vertical velocity at the divide site. This research was supported by U.S. National Science Foundation grants OPP-9615454, OPP-9615417 and OPP-9615502.

\section{REFERENCES}

Bertholds, A. and R. Dandliker. 1988. Determination of the individual strain-optic coefficients in single-mode optical fibers. F. Lightwave Tech., 6(1), 17-20.

Butter, C. D. and G. B. Hocker. 1978. Fiber optics strain gauge. Appl. Opt., 17(18), 2867-2869.

Cutler, N. N., C. F. Raymond, E. D. Waddington, D. A. Meese and R. B. Alley. 1995. The effect of ice-sheet thickness change on the accumulation history inferred from GISP2 layer thicknesses. Ann. Glaciol., 21, 26-32.

Dansgaard, W. and S. J. Johnsen. 1969. A flow model and a time scale for the ice core from Camp Century, Greenland. F. Glaciol., 8(53), 215-223.

Doake, C. S. M. and E.W. Wolff. 1985. Flow law for ice in polar ice sheets. Nature, 314(6008), 255-257.

Glen, J.W. 1958. The flow law of ice: a discussion of the assumptions made in glacier theory, their experimental foundation and consequences. International Association of Scientific Hydrology Publication 47 (Symposium at Chamonix 1958 - Physics of the Movement of the Ice), 171-183.

Hamilton, G. S., I. M. Whillans and P. J. Morgan. 1998. First point measurements of ice-sheet thickness change in Antarctica. Ann. Glaciol., 27, 125-129.

Harrison, W. D. 1975. A measurement of surface-perpendicular strain-rate in a glacier. f. Glaciol., 14(70), 31-37.

Harrison, W. D., K. A. Echelmeyer and H. Engelhardt. 1993. Short-period observations of speed, strain and seismicity on Ice Stream B, Antarctica. 7. Glaciol., 39(133), 463-470.

Meier, M. F. 1958. Vertical profiles of velocity and the flow law of glacier ice. International Association of Scientific Hydrology Publication 47 (Symposium at Chamonix 1958 - Physics of the Movement of the Ice), 169-170.

Nereson, N. A. 1998. The flow history of Siple Dome and Ice Streams C and D, West Antarctica: inferences from geophysical measurements and ice flow models. (Ph.D. thesis, University of Washington.)

Nereson, N. A., E. D. Waddington, C. F. Raymond and H. P. Jacobson. 1996. Predicted age-depth scales for Siple Dome and inland WAIS ice cores in West Antarctica. Geophys. Res. Lett., 23 (22), 3163-3166.

Nereson, N. A., C. F. Raymond, R. W. Jacobel and E. D. Waddington. 2000. The accumulation pattern across Siple Dome, West Antarctica, inferred from radar-detected internal layers. f. Glaciol., 46(152), 75-87.

Paterson, W. S. B. 1976. Vertical strain-rate measurements in an Arctic ice cap and deductions from them. F. Glaciol., 17 (75), 3-12.

Paterson, W. S. B. 1994. The physics of glaciers. Third edition. Oxford, etc., Elsevier.

Raymond, C. F. 1983. Deformation in the vicinity of ice divides. F. Glaciol., 29(103), 357-373.

Raymond, C. F., J. C. Rogers, P. L. Taylor and B. Koci. 1994. Vertical strain measurement in core holes. Natl. Inst. Polar Res. Mem., Special Issue 49, 234-240.

Raymond, C., B. Weertman, L. Thompson, E. Mosley-Thompson, D. Peel and B. Mulvaney. 1996. Geometry, motion and mass balance of Dyer Plateau, Antarctica. 7. Glaciol., 42(142), 510-518.

Reeh, N. 1989. A flow-line model for calculating the surface profile and the velocity, strain-rate, and stress fields in an ice sheet. F. Glaciol., 34(116), $46-54$.

Rogers, J. C. and E. R. LaChapelle. 1974. The measurement of vertical strain in glacier bore holes. F. Glaciol., 13(68), 315-319.

Rüeger, J.M. 1990. Electronic distance measurement. Third edition. Berlin, etc., Springer-Verlag.

Vaughan, D. G., H. F. J. Corr, C. S. M. Doake and E. D. Waddington. 1999. Distortion of isochronous layers in ice revealed by ground-penetrating radar. Nature, 398(6725), 323-326.

Waddington, E. D., C. F. Raymond, D. L. Morse and W. D. Harrison. 1996. Flow law for ice at low deviatoric stress, and implications for ice divide and ice core studies. [Abstract.] Eos, 77(46), Fall Meeting Supplement, F196.

Wingham, D. J., A. L. Ridout, R. Scharroo, R. J. Arthern and C. K. Shum. 1998. Antarctic elevation change 1992 to 1996. Science, 282 (5388), 456-458.

Wolff, E.W. and C. S. M. Doake. 1986. Implications of the form of the flow law for vertical velocity and age-depth profiles in polar ice. 7 . Glaciol., 32(112), 366-370.

Zumberge, M. A. 1997. Precise optical path length measurement through an optical fiber: application to seafloor strain monitoring. Ocean Engineering, 24(6), 531-542.

Zumberge, M. A. and F. K. Wyatt. 1998. Optical fiber interferometers for referencing surface benchmarks to depth. Pure and Applied Geophysics (PAGEOPH), 152(2), 221-246.

Zumberge, M. A., F. K. Wyatt, D. X. Yu and H. Hanada. 1988. Optical fibers for measurement of earth strain. Appl. Opt., 27(19), 4131-4138. 